\title{
COLETTE REVISITADA
}

\section{Angela Li Volsi}

RESUMO: Um olhar lançado subre a trajetória singular da vida e obra cle Colelle (Gabrielle-Sicunie Colette - Saint Sauveur-en-Puisaye, 1873; Paris, 1954), que resgata um insuspeitacto lado estóico, invisível à primeira vistn.

A obra de Colelle é vista como um verdadciro caminho iniciático, visando recuperar uma sabcdoria ancestral, legado que a autora recebeu de sua mâe, Siclo, que a iniciara à comunhão com a natureza.

Estou relendo Colelle, como um dever de casa que me impus nestas férias. E recebo de presente as deliciosas sensações experimentadas há mais de trinta anos, quando pela primeira vez descobri este universo que me prendeu com sua magia até se esgotar a última linha disponível. Passaram-se trinla anos, agora resla-me a obrigação de saber interrogar o resultado dessa longa decantação.

Não é difícil entender por que a magia da palavra de Colette continua intacla. É que sua palavra lem a ressonância e o peso específico de uma moeda que tem seu lastro em ouro. Para nós, pobres leitores pós-modernos bombardeados pelos apelos dos mass-media e adulados por cantos de sereia de todos os tipos a nos promelerem o paraíso, a palavra de Colette tem o mesmo efeito terapêutico de um bálsamo milagroso. Ela nos traz de volta o sabor esquecido de produlos que andam cada vez mais escassos: autenticidade, bom-senso, simplicidade, comunhão com a natureza, solidariedade humana. O lastro da palavra de Colette está depositado em cada erro cometido, em cada lição aprendida, em cada dor experimentada, em cada dolorosa renúncia.

Durante muito tempo ela foi julgada só pelos erros que o moralismo estreito de sua época não the perdoava, incapaz de reconhecer em cada um deles os passos de um caminho iniciálico, que sua obra revela, à condição de ser considerada em sua tolalidade.

O que me proponho é tentar visualizar, através de um rápido retrospecto da vida e dá obra, a trajetória dessa iniciação.

Embora Coletle tenha se tornado muito popular com a famosa série de suas "Claudine" (C'laudine à l'école - Claudine à Paris - Claudine en ménage - 
('lamedine s'en va), não é aí que vamos poder encontrar a escrilora de corpo inleiro. Essa vocação literária, que Colette nunca procurou espontaneamente, é o frulo do oportunismo de seu primeiro marido, Henry Gauthier-Villars, o famoso Willy. Famoso por ser um grande bon-1rivant, figura obrigatória em todos os acontecimentos sociais de seu meio, teve suficiente laso para pressentir a mina de ouro que se escondia atrís da aparência farouche da jovem bourguignonne, com pretensões à independência e emancipação e que, acima de ludo, tinha uma curiosidade enorme por todas as manifestações da vida c do amor. A jovem senhora Willy foi direlamente transplantada de sua querida Saint-Sauveur-en-Puisaye para a movimentada vida de Paris em plena Belle-Époque, cerlamente sonhando com uma vida de delícias e emoçōes sem fïm. Estas não lice fallaram, mas a maior de lodas deve ter sido descobrir que seu marido, quinze anos mais velho do que ela, tinha o propósito de explorar o lalento literírio da esposa, assim como fazia com um sem-número de outros nègres littéraires de que dispunha, para publicar em seu próprio nome as obras que retribuía a preço de trabalho escravo.

Começou para Colelle um vida de reclusa, em que foi eslimulada, cada vez mais compulsoriamente pelo marido, a pôr no papel os episódlios que cerlamente sábia contar com uma verve única e que só poderiam se referir à sua verde vida de adolescente da província. Willy que, além do faro comercial, linha muito espírito, uma vastíssima experiência mundana e um certo talento literário (que, segundo um comentário da própria Colelte, parece que não conseguia exteriorizar por conta própria), era o (ruto mais legítimo daquela burguesia parisiense. Conhecia como ninguém os ingredientes exalos capazes de satisfazer um certo gosto de perversão que o ócio e a vida fácil favoreciam.

Todos os episódios escabrosos c às vezes inverossímeis que apimentam a sćric das C:latedine foram sem dúvida sugeridos ou aumentados por Willy. Colelle, para lazer jus à fama de mulher libertina que scus livros sugeriam, prestou-se ao jogo de cercar-se de uma aura que justilicasse essa imagem, chegando ao ponto de ter ligaçōes homossexuais com a complacência do marido. Aliás, não é dele a teoria segundo a qual, para que uma mulher aprimore sua sensualidade, nada melhor do que um estágio de aprendizado sáfico? Certamente prestou-se ao jogo até descobrir pela primeira vez que seu marido nunca deixara de traí-la, o que fez ruir todo o castelo de justificalivas que só uma mulher apaixonada é capaz de construir e sustentar.

O primciro impulso, após a separação dolorosa cuja decisão parliu de Willy, foi de dar vazão ao desejo de liberdade e independência, quimera sempre perseguida e nunca alcançada. É o tempo de Coletle no music-hall, da vida nômade, pródiga em experiências dolorosas, pungentes e fascinanles, abundanlemente narradas nas obras Les vrilles de la vigne, L'emers du music-hall, La ragabonde e, mais tarde, Mes apprentissages.

As obras escritas imedialamente após a separação de Willy lêm a marca indisfarçível de uma necessidade de claborar, digerir e exorcizar pela literatura o 

1991.

enorme material de vivência que sua experiência de treze anos ao lado de um homem que - ela mesma diz - não sabe se chama de Maquiavel ou de Fregoli, the trouxera. É evidente que a convivência com Willy não pode ser vista só como uma calástrofe que se lenha abalido sobre a vida de Colette. Sem ele, provavelmente lodas as luzes e sombras de sua verdadeira personalidade não teriam tido oportunidade de vir à tona com lamanha violência e riqueza, embora cerlamente Ienham custado muito sofrimento. Sem Willy, o diamente bruto poderia nunca ter sido lapidado. Ao comparar a verdadeira inocência de sua mãe, Sido, à sua, encontramos na boca de Colette a seguinte frase: "Elle qui ménagea la bête, soigna l'enfant, secourut la plante, il lui fut épargné de découvrir qu'une singulière bête veut mourir, qu'un certain enfant implore la souillure, qu'une des fleurs closes exigera d'êlre forcée, puis foulée aux pieds" ${ }^{\prime \prime}$ Com uma única frase, Colelte nos revela toda a extensão do amadurecimento que suas experiências the trouxeram. Parece que scu longo perambular em busca de si própria, o impulso de se expressar por todas as vias arlísticas de que a nalureza a dolou foram uma necessidade absoluta, e uma calarse benfazeja a the ensinar o verdadeiro caminho de volta às suas raízes, com o precioso fardo de um aprendizado lanto mais valioso quanto mais penoso.

Nessa fase Colelte póde liberar todas as energias de que a natureza a dotara, aprimorando principalmente suas habilidades físicas, quase como uma vingança contra o longo lempo em que ficara enclausurada escrevendo sob as ordens de Willy. Isso lhe permitiu ganhar a vida de maneira quase lúdica, aproveitando seu talento pela música, dança e mímica. O aprendizado ao lado de Willy lalvez seja responsável pela ousadia de represenlar quase nua, o que serviu na verdade para alrair o público que espalhava, deliciosamente escandalizado, sua fama de liberlina. Sem dúvida nenhuma, lambém armazenou experiências preciosas para burilar sua compreensão do ser humano, em contato com os colegas que ela chama de "mes frères étincelants et pauvres".

Após esla fase, aquilo que tinha sido o instrumento de tortura da jovem Colelle, o exercício forçado da literalura, tornou-se a válvula que não só foi aos poucos lhe proporcionando a independência financeira, mas revelou-se o meio de expressão definitivo (embora incompleto, segundo a autora) ao qual permaneceu fiel alć o último dia de sua existência. Não tinha sido lambém o involuntário suporte que the permitira sobreviver à sua primeira, dura experiência conjugal? Em meio ao desmoronar de suas ilusões, longe da mãe, Sido, elerno ponto de referência, e exilada de seu país natal ("J'appartiens à un pays que j’ai quilté", é a melancólica consłalação da autora em Les vrilles de la vigne), a obrigação de reviver as experiências da puberdade fez com que não se interrompesse o fluxo da seiva vital que the vinha do contalo com a natureza, agora transformada em matéria lite-

(1) La naissance du jour. Paris: Garnier-Flammariun, 1960, p. 61. 
rária. Sem dúvida nenhuma, o grande charme das C'luncline, apesar das nolas desloantes, consiste na evocação daquele universo mágico, em que a verdadeira iniciação, sem que a autora o soubesse, se dera no espaço restrito do jardim de Sido.

Outro elo indissolúvel com a nalureza, vilal para a sobrevivência de Colette, foi seu contato com os animais, que merecem um capítulo à parte. Não é por acaso que a primeira obra que a autora assinou com o nome de "Colelte Willy" se intitula Dialogue des bêtes. Seria muito simplório deduzir que Coletle, decepcionada com sua vida sentimenlal e sua vagabundagem no meio da fauna humana dos tempos do music-hall, se compensasse com a fidelidade irrrestrita de seus cães e seus gatos. Sua ligação com os bichos é muito mais visceral, é um dos segredos de sua sabedoria, pois sempre observou o comportamento animal como teria feito com seres humanos, e certamente com resultados mais gratificanles, pois os animais não costumam mentir.

Sem dúvida nenhuma, se Colelte fosse um bicho ela scria um galo. Além de compartilhar com esta espécie animal os olhos pers (mislura de azul com verde), e a graça felina de um corpo clástico, embora robuslo, a identificação se silua muito mais em nível de seus hábilos e sua psicologia. (Vale lembrar que Colelte cresceu embalada pelo apelido de "Minet-Chéri", com o qual Sido carinhosamente a chamava.)

Uma de suas obras-primas se intilula justamente La chatte. Foi escrita em 1933, quando Colette já tinha alcançado a maluridade literária e afcliva e a respeitável idade de sessenta anos. A personagem principal, a gala Saha, é Iratada exatamente como uma pessoa, pois se transforma na rival de Camille, a jovem esposa de Alain, que incorre no crime de se entender melhor com a felina do que com sua jovem mulher. Ao descrever Camille, Coletle evidencia sua vulgaridade e irracionalidade, que a leva a alentar contra a vida do animal, jogando-o pela janela. Para infelicidade de Camille, não só Saha não morre, mas passa a se conslituir na prova irrefutável da verdadeira natureza di mulher. Alain acaba por se separar de Camille e volia à sua magnífica cumplicidade com Saiha, que sem precisar fazer absolutamente nada além de ser fiel à sua natureza felina, demonsIra a todo momento sua enorme superioridade sobre o ser humano. O final da obra é muito significativo: enquanto Saha olha com jeilo humano para Camille que vai embora, Alain brinca com algumas castanhas "d'une paume adroite et creusée en palte".

Numa de suas últimas obras, Colclle escreve que "ce qui louche au chal m'a été poignant et nécessaire". Não é difícil intuir nesła confissão que a presença do animal vai além de uma simples preferência como qualquer outra, mas provavelmente existe uma relação inconsciente com a própria figura de Sido, que sempre era evocada "parée d'enfants, de fleurs el d'animaux", como a autora a descreve em La maison de Claudine.

É um pouco como se a presença de um gato na vida de Colclte garantisse o prolongamento da proteçāo malcrna. Aliás, num curioso episódio narrado pela autora, numa das poucas vezes em que mandou chamar uma vidente, esla, que 

1991.

não cra das mais brilhantes, após ter-se desculpálo por não conseguir naquele momento ver grande coisa, acabou descrevendo com detalhes a última gata que Colelle tivera e que, segundo a vidente, continuava a ocupar seu lugar aos pés da dona mesmo depois de morta. Numa visita posterior da vidente, Colette não ousa perguntar se a gala continua no mesmo lugar, de medo de descobrir não ser mais digna da presença do animal.

Esła noção de ser ou não "digna" de alguna coisa, só aparece em Colelte com relação a seus laços com a vida vegetal ou animal. Nunca está ligada a problemas de moral ou de religião, o que só reforça uma absoluta ausência de inquietação metafísica:

Maison et jardin vivent encore, je le sais, mais qu'importe si la magie les a quiltés, si le secret est perdu qui ouvrail, - lumière, odeurs, harmonie d'arbres et d'oiseaux, murmure de voix humaines qu'a déjà suspendu la mort, - un monde donl j'ai cessé d'êlre digne?...2

Mas voltemos ao rastreamento dos apprentissages de Colelte. Durante o tempo que ela passa trabalhando no music-hall, quem a ajuda a cicatrizar as feridas do primeiro casamento é a marquesa de Belbeuf (a famosa Missy), que a põe a salvo de seu medo (provisório) dos homens e cerlamente a socorre com ajuda material. Essa ligação dura até o momento em que o coração da vagabonde volta a bater por um homem. Em 1911, conhece o barão Henry de Jouvenel, saindo de um primeiro casamento fracassado, pai de dois filhos (de mães diferentes) e coredator chefe do jornal Le matin. A paixão é recíproca e quando Colette, aos 39 anos, percebe que está esperando seu primeiro filho, o casamento se impõe. Alguns meses após o casamento morre Sido, e o nascimento de sua filha, Coletle de Jouvenel, traz-lhe providencialmente um novo sopro de vida.

A maternidade foi vivida por Colette com o mesmo encantamento que todo fenómeno da natureza lhe provocava, mas não foi suficiente para desviar sua vida do rumo que já estava traçado. Em $L \cdot E ́$ toile Vesper, uma de suas últimas obras cuja larefa principal é passar a limpo todo o passado para reconstituir o verdadeiro significado de sua vida, encontramos uma confissão muito sincera a este respeito:

Mon brin de virilité me sauva du danger qui expose l'écrivain, promu parent heureux et tendre, à tourner auteur médiocre, à préférer désormais ce que récompense une visible el malérielle croissance: le culte des enfants, des plantes, des élevages sous leurs formes diverses. Un vieux garçon de quarante ans, sous la femme encore jeune que j'élais, veilla au salut d'une 
partic peul-être précieuse. Quand j'élais jeune, si je m occupais, par exception, à un ouvrage d'aiguille, Sido hochail son front divinateur: "Tu n'auras jamais l'air que d'un garçon qui coud". Ne m'eûl-clle pas dil: "Tu ne seras jamais qu'un écrivain qui a lait un cnfant"? Elle ln'aurait pas ignoré, elle, le caractère accidentel de ma maternilé ${ }^{3}$

Colette, que continuara a trabalhar no music-hall alé o nascimento da fiIha, a partir deste momento é introduzida pelo marido na carreira jornalística, pois é convidada a colaborar no Le Metin. Com o advento da guerra, Jouvencl é chamado ao front e Colette permancee firme em scu posto para garantir a subsistência da família. É dessa época sua viagem a várias cidades da Ilália, enviada pelos jornais La Vie Parisienne e Le Matin. O resullado ć uma sćrie de artigos sob o lílulo de "Impressions d'Italie" "

Com o fim da guerra, Jouvenel encaminha-se para uma carreira política que Colette não poderia compartilhar por absolula filla de interesse e, principalmente, porque seu segundo marido se revela bastante inconstante em matéria de vida amorosa. Ela ainda suporta algumas situaçōes constrangedoras, mas também este segundo casamento se conclui com o divórcio cm 1924 . Em decorrência da separação, Colette perde também seu cargo no Le Matin.

Neste ínterim, sua fama de grande escritora tinha se firmado definilivamente graças ao sucesso de Chéri, uma de suas obras-primas, publicada inicialmente em capítulos semanais no jornal La Vie Parisienne em janciro de 1920. Mais tarde é Iransformada em peça de teatro, tendo Colette representado várias vezes o principal papel feminino, Léa. (C.héri conheceu também uma transposiçĩo cinemalográfica que não parece ter tido o mesmo sucesso.)

La maison de Clandine representa uma espécie de vingança de seu tempo de escravidāo como nègre de Willy. Trala-se agora da vercladeira cisa de Colelle adolescente, sem as inlervençōes picantes e deliberadamente ousadas que o estilo de Willy lhe impusera. O reino encanlado animado pelo espírito de Sido ressurge intacto, numa espécie de ritual de purificação.

Em 1925, para conseguir superar seus problemas financeiros, Colette volta ao teatro para representar Chéri. É neste ano que conhece Maurice Goudekel, dezessete anos mais novo do que ela. Estamos finalmente diante da clapa delinitiva que marca a eslabilidade afetiva para nossa autora, pois encontra $\mathrm{cm}$ Goudeket mais do que um novo amor. Aquele que atć o fim da vida cla chamará de "mon meilleur ami" dedica praticamente toda sua vida a ser o fiel escudeiro dessa mulher cuja obra tinha lido com dezesseis anos de idade, e que nunca deixara de admirar. Coletle experimenta uma fase de verdadeira plenilude, de longas estadias

(3) L'Etoile Vesgmer. Genève: Editions du Milieu du Munck, 1946, p. 210. 

1991.

nas regiões da França que mais ama e de grande altividade literária. Agora a vida em contato com a natureza e o ofício de escritora estão intimámente ligados.

A partir desse momento, a produção literária é mais intensa e constante (La seconde - 1929; Sido - 1929; Dıo - 1934; Le toutounier - 1939; C'hambre d'hôtel 1940; Journal à rebours - 1941; Julie de Carneilhan - 1941; Paris de ma fenêtre 1942; Le képi - 1943; Gigi (uma de suas obras máis célebres, levada ao teatro e ao cincma com sucesso) - 1944; L'étoile Vesper - 1946; Le fanal blen - 1949).

As mais significativas para se compreender a evolução da autora são sem dúvida La fin de Chéri (1926) e La naissance du jour (1928).

La fin de C.héri retoma, seis anos depois, a célebre estória de Chéri, o bem nascido jovem de 24 anos iniciado aos mistérios do amor por Léa, uma esplêndida mulher com o dobro de sua idade, melhor amiga de sua própria mãe, que o mima c o sustenta como a um belíssimo animal de estimação. Chéri terminava no momento em que o jovem, que tinha se deixado convencer pela mãe a realizar um casamento de conveniência, sai da casa de Léa pela última vez olhando para o céu e estufando o peito como um preso que readquire a liberdade. Na obra seguinte, assistimos ao desastre matrimonial de Chéri, agravado pela sensação de inutilidade de sua vida, que conhecera lambém a experiência de uma guerra. Após seis anos sem nenhuma notícia, Chéri toma de repente, como a última esperança de um náufrago, a decisão de rever Léa. Ele é introduzido por uma empregada na sala em que já se encontram duas senhoras:

Une femme écrivait, le dos tourné, assise devant un bonheur-du-jour. Chéri distingua un large dos, le bourrelet grenu de la nuque au-dessous de gros cheveux gris vigoureux, taillés comme ceux de sa mère. "Allons bon, elle n'est pas seule. Qu'est-ce que c'est que celte bonne femme là?"

- Mcts-moi aussi par écrit l'adresse, Léa, et le nom du masseur. Moi, tu sais, les noms...

Une femme en noir, assise, venait de parler, et Cluéri sentit en lui-même un remous précurseur. "Alors... où est Léa?"

La dame au poil gris se retourna, et Chéri reçut en plein visage le choc de ses yeux bleus.

- Eh! mon Dieu, petit, c'est toi?

Il avança comme en songe, baisa une main.

- Monsieur Frédéric Peloux, la princesse Cheniaguine.

Chéri baisa une autre main, s’assit.

-C'est?... questionna la dame en noir, en le désignant avec autant de liberté que s'il eât été sourd.

Le grand rire innocent résonna de nouveau, ct Chéri chercha la source de ce rire, là, ici, ailleurs, partout ailleurs que dans la gorge de la femme au poil gris...

- Mais non, ce n'est pas! Ou ce n'est plus, pour micux dire! Valérie, voyons, qu'est-ce que tu vas chercher? 
Elle n'élail pas monstrueuse, mais vaste, ét chargée d'un planlureux développement de toules les parties de son corps. Ses bras, comme de rondes cuisses, s'écartaient de ses hanches, soulevés près de l'aisselle par leur Épaisseur charnue. La jupe unie, la longue veste impersonnelle entr'ouverte sur du linge à jabot, annonçaient l'abdication, la rétraction normáles de la féminité, el une sorte de dignité sans sexe.

Léa se tenait deboul entre Chéri el la fenêtre, el sa masse consistante, presque cubique, ne le consterna point d'abord. Lorsqu'elle bougea pour atleindre un siège, elle dévoila ses trails, et il se mit à l’implorer mentalement comme îl eût imploré un fou muni d'armes. Rouge, d'un rouge un peu blet, elle dédaignait à présent la poudre, et riait d'une bouche pleine d'or. Une saine vieille femme, en somme, à bajoues larges et à menton doublé, capable de porter son fardeau de chair, libre d'étais et d'entraves ${ }^{4}$

Após uma constrangedora conversação a três, a princesá vai embora e os dois ficam sozinhos:

Il se sentait pâle, et la peau raidie autour de la bouche, ainsi que par un grand froid. Il retenait un terrible élan de rancune el de supplicalion, le besoin de crier: "Cesse! Reparais! Jelle celle mascarade! Tu es bien quelque part là-dessous, puisque je l'entends parler! Eclos! Surgis toule neuve, les cheveux rougis de ce matin, poudrée de frais; reprends ton long corset, ta robe bleue à fin jabot, ton parfum de prairie que je quête en vain dans ta nouvelle maison... Quille tout cela, viens-l'en, à travers Passy mouillé, ses oiseaux et ses chiens, jusqu'à l'avenue Bugeaud, où sûrement Ernest fait les cuivres de ta grille..." Il ferma les yeux, à bout de forces ${ }^{5}$

Inútil dizer que para Chéri o encontro serve para the restituir, ainda mais terrível e irremediável, todo o peso de sua vida sem sentido. Ele ainda se arrasta por algum tempo entre sua vida de casado e alguns encontros melancólicos e destrutivos, até que, não conseguindo encontrar as forças para recompor sua vida, acaba se suicidando.

La fin de C.héri é a primeira obra em que podemos identificar, na caracterização da personagem feminina, a imagem de uma Colette que aceila quase com alívio o fim da luta amorosa.

A obra que the serve de contraponto e representa a chave de toda a produção litcrária de colette foi escrita dois anos depois, em 1928. Trata-se de La nais-

(4) La fin de Chici. Paris: Flammarion, 1953, pp. 91/9.3.

(5) Id., pp. 101/102. 

1991.

sance du jour, a única obra que, confessadamenle, cuslou à autora o maior esforço de criação e uma angústia inédila. Aqui o corajoso retrato, sem retoques, de uma Colelle que já abdicou da luta com seu cher ennemi, como costumava se referir ao homem por quem eslava apaixonada, já esla definido. Goudekel, no livro em que compartiltha sua experiência de viver ao lado da escritora, faz o seguinte comentário:

... Le singulier livre! Il a élé commencé en 1927, à Saint-Tropez, sur les licux qu'il décrit, ce qui, dans l'ouvre de Colette est exceptionncl, car ẹlle voyait mieux, même les paysages, avec quelque recul. Si jamais roman a paru aulobiographique, c'est celui-là. Toul y esı, "la Treille Muscate", le jardin, la vigne, la terrasse, la mer, les bêtes. Nos amis y portent leurs noms réels. Colette s'y met en scène, s'y peint avec la dernière exactitude. Elle n'a jamais poussé si loin l'analyse d'elle-même. Les allusions à son passé, transparentes, sont véridiques. Les lettres de Sido reproduisent celles que Sido écrivil. Les odeurs sont celles qui flattent encore mes narines, j'ai connu ces nuits bleues, j'entends le crépitement des cigales, je subis l'assaut du vent, ma main s'attarde sur le mur tiédi. Tout y est, sauf que $L a$ naissance du jour évoque la paix des sens et un renoncement à l'amour, dans le moment que Coletle et moi vivions ensemble des heures ardentes, exaltées par la chaleur, la lumière, le parfum des étés provençaux.

La réserve qu'elle a toujours observée, quand il s'agit de ses sentiments profonds, nest pas seule en cause. Je tiens pour certain que ce renoncement, elle l'avait envisagé. Moins par sagesse, car clle avait le goût du risque, que par une propension à éloigner ce qu elle convoilait le plus. Entre prendre et se déprendre, entre tenir el écarter, elle a souvent balancé. "Le difficile, disait-elle, ce n'est pas de donner, c'est de ne pas tout donner".

Qu'on n'aille pas, surtout, voir là un penchant ì la morlification, ou alors il faudrail admetlre qu' un cerlain jansénisme demeure inscril dans le sang de tout Francais, si libre soit-il. Dieu merci, Colette élait douée d'un solide appélit pour les biens de cette terre - je ne crois pas d'ailleurs que ce soient les tièdes qui le plus volontiers renoncent - et tirait de lẹur possession un franc plaisir. Mais en même temps l'habilait une secrète austérité, et l'heure, pour notre couple, de muer l'amour en amitié, c'est elle qui en a, plus tard, avant moi décidé.

De tous les livres de Colelte, c'esı celui que je préfère. J'y vois, au centre de son oeuvre, la fleur de sa pleine maturité. Baigné de poésie, d'une densité, d'une richesse, d'une ćloquence sans égales, La naissance du jour a failli ne devenir qu'une longue offrande lyrique de Colelte à ses dieux lares. Ayant promis à ses éditeurs un roman, elle crut devoir - et c'est dommage - y introduire une affabulation. Celle-ci est mince. Le personnage de Vial, en particulier, reste assez inconsistant. Je n'en suis pas le modèle, comme on l'a cru, et ne pouvais l'être. Je reconnais en Vial un jeune anti- 
quaire de Saint-Tropez, mais ma présence constituait une gêne pour que le portrait fât bon. Colette n'a commencé à parler de moi que près de vingt ans plus tard, dans $L$ 'Étoile Vesper, sous l'aile de l'amitié'

Segundo Goudeket, a coincidência entre autora e personagem é quase total. No entanto, e talvez aí esteja a explicação desse "quase", encontramos na obra a seguinte passagem, imediatamente após uma apaixonada descrição da mancira como Sido vivia seus últimos anos:

... C'e que j'entasse n'est pas du même aloi. Mais ce qui en demeurera provient du filon paralléle, inférieur, amalgamé de grasse lerre, el je n`ai pas trop lardé à comprendre qu' un âge vient où au lieu de s'exprimer toute en baumes, en pleurs mortels, en soulfle embrasé el décroissanl, sur les beaux pieds qu'elle embrassait, impatients de courir le monde, - un âge vient où il n'esı plus donné à une femme que de s'enrichir.

Elle entasse, elle recense jusqu'aux coups, jusq'aux cicalrices - une cicatrice, c'est une marque qu'elle n'avait pas en naissant, une acquisition. Quand elle soupire: "Ah! que de peines II m'a données!" elle pèse, malgré elle, la valeur du mot, - la valeur des dons. Elle les range peu à peu, harmonicusement. Le temps, et leur nombre, font qu elle est obligée, dans la mesure où son trésor s'accroît, de se reculer un peu de lui, comme un peintre de son oeuvre. Elle recule, et revient, et recule, repousse à son rang quelque scandaleux détail, altire au jour un souvenir noyé d'ombre. Elle devient, - par un art inespéré, - ćquitable... Immgine-t-on, à me lire, que je fais mon portrait? Patience: c'est seulement mon modele" ${ }^{7}$

Nesse trecho há duas revelações capitais para a compreensão da totalidade do processo criativo de Colette. No primeiro enunciado grifado encontramos a irremediável certeza, outras vezes expressa no tom pungente de quem não se julga digno de uma graça, de sua inferioridade com relação a Sido. É esse o sentimento que perpassa a obra toda, e a compensação à frustração dele decorrente é o que justifica a própria criação literária da autora.

A segunda revelação imporlante está contida na conclusão do trecho. Sua leitura admite pelo menos duas interpretações: a primeira é que Colclte tem plena consciência de que o modelo do qual quer se aproximar é Sido. A segunda, mais difícil de demonstrar, parece fazer referência às várias camadas coexistentes $\mathrm{cm}$ cada ser humano. Eslá aí embutida toda a distância que existe entre autor, narrador e personagem, mesmo quando a obra é declaradamente autobiográfica. Pelo

(6) Goudekel, Maurice. Press de Colette. Paris: Flammarion, i956, pp. 51/53.

(7) Op. cit., pp. 70/71, grifos meus. 

1991.

simples falo de ter passado pelo processo da criação artíslica, essas três insłâncias nunca podem coincidir. E é por essa razão que o verdadeiro "eu" do artisla só pode se revelar na obra, que acaba sendo literalmente uma questão de vida ou morle. Nos interstícios entre uma instância e outra está toda a riqueza e a impalpabilidade do mundo inconsciente, e a verdadeira arte consiste em Iransmitir esse mundo ao leilor.

No momento em que Colelle esłá no auge de sua vida afetiva e profissional, volla-se cada vez mais para sua vida interior e deliberadamente determina que sua convivência com o marido se aproximará muilo mais de uma relação de amizade do que de uma relação amorosa. A partir do momento em que depõe as armas dessa luta incessante que o amor representara em sua vida, pode se dedicar a sua verdadeira tarefa. E esta tarefa é a de recuperar todos os anos de equívocos e de desvios, em que se deixara ofuscar por luzes falsas e por guias espúrios, para vollar com toda sua alma para o verdadeiro guia, a mãe, que se confunde com a natureza.

Não é preciso recorrer a grandes estudos psicanalíticos para detectar em Colette uma espécie de obsessão pela figura materna. Ela própria a chama, em Journal à rebours, "le personnage principal de toute ma vie".

La naissance du jour, este romance que na verdade é um longo poema de amor dedicado à sua querida ausente, começa dando a palavra a Sido:

Monsieur,

Vous me demandez de venir passer une huilaine de jours chez vous, c'està-dire auprès de ma fille que j'adore. Vous qui vivez auprès d'elle, vous savez combien je la vois rarement, combien sa présence m'enchante, et je suis touchée que vous $m$ 'invitiez à venir la voir. Pourtant, je $n$ 'accepterai pas votre aimable invilation, du moins pas maintenant. Voici pourquoi: mon cactus rose va probablement flcurir. C'est une plante très rare, que l'on m'a donnée, et qui, m'a-t-on dit, ne fleurit sous nos climats que tous les qualre ans. Or, je suis déjà une très vicille femme, el, si je m'absentais pendant que mon cactus rose va fleurir, je suis certaine de ne pas le voir refleurir une autre fois...

Veuillez donc accepter, Monsicur, avec mon remerciement sincère, l'expression de mes sentiments distingués el de mon regret.

Ce billet, signé "Sidonic Coletle, née Landoy", fut écrit par ma mère à l'un de mes maris, le second. L'annće d'après, elle mourait, âgée de soixantedix-sepl ans.

Au cours des heures ou je me sens inférieure à toul ce qui m'entoure, menacée par ma propre médiocrilé, effrayée de découvrir qu'un muscle perd sa vigucur, un désir sa force, une douleur la trempe affilée de son tranchant, je puis pourtant me redresser et me dire: "Je suis la fille de celle qui ćcrivit cette letlre, - celle lellre el lant d'autres, que j'ai gardées. Celle-ci, 
en dix lignes, m'enseigne qu'à soixante-seize áns elle projelail cl culreprenail des voyages, mais que l'éclosion possible, l'allenle d'une fleur tropicalc suspendail tout et laisail silence même dans son cocur destiné à l'amour. Je suis la fille d'une femme qui, dans un petit pays honkeux, avare el resserré, ouvrit sa maison villageoise aux chals errants, aux chemineaux el aux servantes enceinles. Je suis la fille d'une femme qui, vingt fois désespérée de mancuer d’argent pour autrui, courul sous la neige foucllée de vent crier de porte en porte, chez des riches, qu un enlant, près d'un âtre indigent, venait de naîlre sans langes, nu sur de délaillantes mains nues...

Puissé-je noublier jamais que je suis la fille d'une telle femme qui penchait, tremblante, toutes ses rides éblouics entre les sabres d'un cactus sur une promesse de fleur, une lelle femme qui ne cessa elle-même d’éclore, infatigablement, pendant trois quarts de siècle...

Qualquer análise, qualquer comentário, seria pobre diante da força desse grito. O resto da vida será ainda pouco para Colette tenlar apagar os vestígios de tudo aquilo que a distanciara de Sido.

A renúncia ao amor é o primciro passo cm direção à identidade tão descjada:

A n'en pas douter, ma mère savail, elle qui n’apprit rien, comme clle disail, "qu'en se bralant", elle savait qu'on possède dans l'abslention, et sculement dans l'abstention. Abstention, consommalion, le péché n'est guère plus lourd ici que là, pour les "grandes amourcuses" de sa sorte, - de notre sortè

Para cumprir sua verdadeira tarefa, Coletle teve por aliada a provação física que para muitos pode ser vista como um infortúnio ou, quem sabe, como o merecido castigo por uma vida de dissipações.

É a partir de 1939 que ela começa a se queixar dos primeiros alaques da artrite que a imobiliza quase completamente a partir de 1943. Desde os anos 30 Cole lle já alcançara a plenitude de sua arte literária e o reconhecimento da crítica, após muitos anos de hostilidade e discriminação, provocadas principalmente pelo preconceito com relação à sua maneira de viver. É bem verdade que a Académie Française não quis se curvar a seu talento. Em compensação, loi recebida pela Académic Royale Belge cm 1936, para ocupar o lugar deixado vago com a morle da poetisa Anna de Noailles. A Académic Goncourl, após algumas tentativas frustradas, a recebeu em 1945. (Em 1949 Colelle tornou-se Presidenle desta Academia, cargo que ocupou até ofim de sua vida.)

(8) Op. cir., pp. $37 / 38$.

(9) Id., p. 60). 
Além de se dedicar incansavelmente a lodas as tarefás decorrentes de sua profissão de jornalista e seu ofício de escrilora (viagens, reportagens, entrevistas, conferências, palestras, inauguraçócs, eventos cullurais a sociais), quis também satisfazer o desejo de montar uma empresa própria de produlos de beleza. Foi na época de seu último casamento. Goudeket narra em seu livro como, conhecendo Colelle e embora prevendo o fracasso da empreilada, deixou que levasse alé o fim a experiência, para que chegasse sozinha à conclusão de que os resultados obtidos não compensavam minimamente o trabalho insano que a empresa exigia. É que Colelte nunca tinha esquecido a experiência traumálica, em criança, de ver todos os perlences da família serem leiloados para pagar as dívidas que seu pai não soubera saldar. Provavelmente remonla a esse episódio uma constante preocupação em sentir sua vida apoiada em sólidas bases financeiras, o que sempre a compeliu a deixar em ordem absoluta, alć o momento da morte, todas suas contas.

Sua natureza irréquicta e a constante necessidade de ação fizeram com que se entregasse com delícia às várias modalidades de bricolage doméstico que a encanlavam. As várias mudanças de cassa sempre foram feitas sob sua vigilante supervisão e, como num passe de mágica, em pouco lempo ludo ficava perfeitamenle cm ordem. (Há uma passagem curiosa em que Sido, ao visilar a lilha, critica a ordem excessiva de seus armários.) Tudo o que se referisse à vida comum do dia-a-dia merecia seu entusiasmo e sua participação: a limpezal doméstica, a decoração, a moda e, principalmente, tudo o que se referisse aos alimentos, desde sua semeadura alé a colheila, o preparo e o consumo. Sempre leve alguma casa de canpo ou de praia em que podia dar vazão a seu descjo de conlalo com a mãc terra.

Com todo esse fervilhar de atividades e interesses, não é dilícil imaginar o que deveria ter representado para cla a imobilidade forçada. Pois é diante dessa prova terrível que Colelte mostrou ser a digna filla de Sido. Chegou ao ponto de demonstrar com relação à doença a mesma curiosidade que todos os outros fenômenos da natureza the haviam desperlado. Nãe só sempre se recusou a tomar analgésicos, mas só diminuiu o ritmo das alividades naquilo que dependesse exclusivanente de suas pernas. É como se tivesse accito o desafio proposto por essa nova entidade que se instalara em sua vida.

Eis como se refere a essa experiência em sua obra $L$ Étoile Vesper:

Il y a dans la doūleur manifestée par ćlancements ou par ondes, une contribution de rythme que je ne puis lout entière maudire, un flux, un reflux dont l'indépendance occupe toute mon attention. Ce que j'appelle souffrir honorablement, e'est mon dialogue avec la présence d'un mal. Deboul, elle m'empêche de marcher, mais couchéc je lui tiens têle. La preuve c'est l'absence à mon chevet d'analgésique ou de somnifère. De ce me mbre que tu tourmenles, doulcur, j’ai sáuf quelques défaillances de ma volonté al- 
tendu que tu te rétires et tu t'es retirée. Tu n'as pas pu faire encore que mon sommeil soit embourbé, ma langué amère, mon sommeil troublé de pâles el suspectes merveilles

A artrite não a impediu, por exemplo, de continuar presidindo a Académie Goncourt e de participar dos famosos almoços, aos quais comparecia carregada pelos seus colegas acadêmicos. Passou os últimos dez anos da vida no seu divanradeail, no qual ela dizia navegar rumo a lodas as direções para onde sua fanlasia e sua arte a levavam. Os últimos anos da vida de Coletle devem ser imaginados com a autora instalada em seu apartamento do Palais-Royal, do qual avistava todo o jardim fervilhante de crianças, pássaros, plantas e flores na boa estação, e neve no inverno. A bordo de seu sofá-jangada administrava uma vida intensa de atividade literária, visitas constantes de amigos e admiradores, o trabalho paciente de confeccionar elaboradas tapeçarias que iam enfeitar sua casa, e a curiosidade nunca saciada de ler livros de bolânica, zoologia, história natural cujas ilustraçōes não se cansava de olhar.

E é desse novo ponto de observação, imóvel só em aparência, que Colette tem a oporlunidade de completar sua viagem iniciálica que começara no jardim de Sido. Face a face com a fragilidade física, aquictado o frenesi de atividades a que seu anligo vigor a compelia, ela pode finalmente deixar aflorar toda a reserva de sabedoria e solidariedade humana que sua primeira infância já lhe legara.

Em sua obra Paris de ma fenêtre (escrita cm 1942), ela deixa se expandir loda a ternura que sempre the inspiraram os mais humildes, os "diferentes". É aí que vamos encontrar uma série de relatos trayicômicos de episódios relativos à resistência francesa durante a segunda Guerra Mundial. De sua caneta não surgem considerações filosófico-socializantes sobre a siluação, mas o lestemunho precioso de alguém que sentiu na pele a sensação de ser acordada $\mathrm{cm}$ plená noite e receber a visita da Gestapo que vem buscar o marido que comelera o crime de ser judeu. Sem uma única concessão à autopiedade, Colette se preocupa ao contrário em compartilhar com os vizinhos, companheiros de infortúnio, os bens de que dispõe e, sobretudo, o tesouro dos mil pequenos conselhos práticos para amenizar os rigores da situação.

De seu relato enxuto surge loda a força de uma raça de que ela compartilha o orgulho, a habilidade em dar soluçōes originais a siluações inédilas e, tempero delicioso sabiamente salpicado, o Iraço humorístico que lorna inesquecíveis personagens e acontecimentos. Sem a experiência da dor lísica a mortificar 0 antigo orgulho de seu corpo elástico e sensual, talvez a solidaricdade com o sofrimento alheio não tivesse encontrado o mesmo espaço cm sua obra.

Agora ela tinha a paz necessária para empreender o caminho de volta e reencontrar, uma a uma, lodas as pegadas que a conduziram alé aí, desfazendo interiormente muitos dos equívocos e dos caminhos que a linham afaslado de Sido, sua elerna esırela-guia. À medida que envelhece, é com Sido que anseia se pare- 

1991.

cer cada vez mais, até fisicamente, numa contínua demonstração de que ná verdade nunca tinha se afastado de seu lado.

Chegados a este ponto, a comparação com Proust, do qual Colelle foi conlemporânea, lendo nascido só dois anos depois, é inevilável. São inúmeros os pontos de conlalo que só tornam mais evidentes as diferenças entre os dois. Sem prelender fazer uma lista exaustiva, comecemos pelas semelhanças:

Colette, cheia de vida mas apaixonada e submissa ao marido, é obrigada a se enclausurar e a recorrer voluntariamente a suas memórias recentes. A obra produzida é um produto espúrio, motivado pela ganância do marido, mas ao mesmo tempo faz vir à tona o talento literário desconhecido pela autora. Proust, doente e duplamente infeliz: por não considerar-se capaz de realizar a obra literária que persegue, c pela morte da mãe, consegue finalmente descobrir a chave que abre a porla de seu processo criativo e enclausura-se voluntariamente para fazer ressurgir o edifício imenso das recordações.

A conslante curiosidade e um agudo senso de observação fazem com que os dois registrem os mínimos delalhes à sua volta. A predominância, sobre lodos os outros sentidos, do olhar, atrai como um imã as pessoas $\mathrm{e}$ as coisas e as captura em toda sua essência.

Ambos os autores mobilizam a linguagem em toda a riqueza de seus matizes, num esforço para reproduzir o mundo em todas as suas dimensões. Lamentam não poder dispor ao mesmo tempo de lodos os recursos das oulras artes em conjunto. Para suprir a essa limilação, lançam mão da técnica utilizada pela pintura impressionista que, a partir de efeitos produzidos por uma série de toques sobrepostos, faz surgir o objeto em sua totalidade, emprestando-lhe a luz, a cor, o sabor, o odor, o som, a textura que o autor quer transmitir. A sensibilidade musical que ambos possuem em alto grau lhes sugere o ritmo que empresta à frase a cadência exata, e restitui à palavra seu poder encantatório. Este ritmo, no entanto, se traduz por uma respiração do narrador que é peculiar a cada um e imprime ao texto sua marca única.

Tanto Proust como Colette lêm um talento indisculível para a imitaçĩo, decorrente de seu espírito de observação que, por sua vez, ć o corolário da atitude humorística que os dois assumem diante da vida. Se admitirmos que o humor é, em última análise, uma atitude de superioridade diante da vida, que permile reduzir esta última às suas verdadeiras dimensões, após ter avaliado a precariedade da condição humana (o que pressupõe um profundo conlhecimento de si próprio), devemos reconhecer em escritores do porte de Proust c de Coletle um inegável talento de humoristas.

Na medida em que não existe "o humor", mas manifestações humorísticas tão variadas quanto o são os indivíduos. e considerando a extração completamente diferente dos dois autores, é evidente que não se pode comparar a expressão humorística de Proust à de Colette, assim como seus estilos são únicos e inconfundíveis. Esse talento comum, no entanto, os aproxima na mestria com que sabem criar o perfil das irresislíveis personagens que animam seu universo e, 
principalmente, na infinidade de observaçōes tão sulis que às vezes são imperceplíveis à primcira vista.

No verdadeiro tralado de eslétical que é Le Temps Retrunlé, Proust sinteliza de mancira definitiva a questão do cstilo:

... car le style pour l'ecrivain, aussi bien que la coulcur pour le peintre, est une question non de technique mais de vision. Il est la révélation, qui serail impossible par des moyens directs el conscients, de la diflérence qualilalive qu'il y a dans la façon dont nous apparât le monde, diflérence qui, s'il n'y avail pas l'arl, resterait le secret élernel de chacun ${ }^{10}$

Os dois tinham uma admiração incondicional por Balzac, o grande mestre da representação realista. O que faz a grande originalidade e superioridade de ambos com relação ao mestre é a percepção de que nada pode ser considerado fruto de um determinismo cego. Ao contrario, pressentindo a imporlâncial do mundo inconsciente, souberam reproduzir o fragnentário e o intermilente da natureza humana, o que faz de seu universo o espelho real da grandeza c da miséria do animal chamado homem.

No que diz respeito à concepção do amor, parece que para os dois o amor é uma espécie de doença inevitável, que só pode trazer o sofrimento, mas cuja ausência também faz sofrer. A este propósito, é incvilável a aproximação de Colelte c Proust pela experiência homossexual que os dois tiveram.

É justamente a partir daqui que começam as diferenças. Com base no que se conhece de sua vida e sua obra, é lícito supor que os motivos que levaram Proust a tal experiência se prendem à sua siluação de lïlho muito querido c muito mimado de uma mãe extremosa, de beleza e inteligência singulares, e que leve a sensibilidade suliciente de pressentir no fitho a essência de uma criatura muito especial e de querer preservá-la. Isso, agravado pelo fato de Proust nunca ter conseguido superar o lemor que lhe inspirava um pai muilo mais velho e autoritário, só pode ler acentuado sua inclinação que o aproximava muito mais do modelo materno do que do paterno.

Coletle, que lambém tem em comum com Proust a admiração incondicional pela figura malerna, admira sobretudo nela o grande apego a todas as manifestaçōes da nalureza, e sua força quase viril que a torna capaz de suprir à fraqueza de um marido idealista c diminuido por uma invalider prematura, provocalda pela guerra.

O resulledo, aliado à diferença de ambiente em que os dois escritores viveram, foi que Proust cresceu com a delicadeza de uma flor de estufia, que qualquer sopro maligno derrubava, enquanto Colelle demonstrou desde a mais tenra idade

(10) Prousl, Marcel. Le Temps Retrou 'é. P'aris: Gallimard, 1954, p. 25.1. 

1991.

uma saúde invejável e um apetite pela vida que a transformou numa verdadeira força da natureza. Sua experiência homossexual nada mais representou do que o desvio momentâneo que a fase "Willy" trouxe $\mathrm{em}$ sua vida, mas nada mais significou além de um breve parênteses sem conseqüûncias.

Além disso, Colette teve a sorte de precisar lutar para sobreviver, o que fez com que recorresse a todos seus lalentos físicos e mentais, colocando em funcionamento e exercitando durante toda a vida todas suas habilidades. Proust morreu, alguém já disse muito maldosamente, por não ter aprendido a abrir uma janela.

A grande diferença entre Colelte e Proust é que este último sacrificou sua vida à arle, que aliás não se cansou de proclamar mais importante do que a própria vida. Coletle viveu plenamente, sem nenhuma vergonha ou sentimento de culpa, ludo o que seus sentidos the sugeriam. Foi levada à literalura quase à revelia, e provavelmente teria se realizado como pessoa sem nunca encontrar o caminho literário. Aliás, precisou lutar muito tempo contra um excessivo pendor para o lirismo, que herdara de seu pai e ao qual não queria sucumbir. Talvez seja seu animus que lhe deu a força de ludo suportar, enquanto a anima de Proust talvez tenha sido um obstáculo para sua plena realização. Os dois eram amorais segundo a ética vigente e ignoravam a angústia da busca de Deus. O que socorreu Colette, entretanto, foi sua constante proximidade com a natureza. Prousi, na minha interpretação, recusou-se a viver a vida de todo mundo a partir do momento em que sua mãe morreu e ele decidiu, para fazê-la reviver e para não morrer lambém, aprisioná-la para sempre em sua reconstrução literária que soube captar a essência do tempo ("un peu de temps à l'état pur"), de modo a lhe permitir a renovação da felicidade indizível que só a memória involuntária podia lhe trazer. Ousaríamos concluir pela superioridade da sabedoria feminina, que a faz instintivamente voltar-se para o lado da vida? Difícil fazer tal afirmação, mas inevitável tecer tais considerações.

Colette, talvez influenciada pelas teorias de Geoffreoy de Saint-Hilaire, tinha a convicção de que o mundo vegetal, animal, mineral e humano têm a mesma natureza (o que a aproxima surpreendentemente de um Diderot). Eis o comovido depoimento de Goudeket:

Nous assistions, au cinéma, à un de ces courts métrages qui montrent des germinations en un moment accomplies, des floraisons qui ressemblent à des luttes, des déhiscences dramatiques. Colette élait hors d'elle. Me serrant fortement le bras, la voix rauque et la lèvre tremblante, elle répétait, avec une intensité de pythonisse: "Iî n'y a qu ume bête! Tu m'entends, Maurice, il n'y a qu'une bête

(11) op. cit., p. 35, grifus do autur. 
Essa forma de panteísmo sem criador preenchia lalvez a necessidade de indagação religiosa, inerente a todo ser humano, quer ele o admila quer não. É certo que Colelle não alimenlava a esperança de conhecer uma vida além da morle, mas sua atilude de grande coragem diante da dor, sua enorme solidariedade humana, lemperada pelo humor que foi sua constante marca pessoal, fazem entrever uma vida espiritual que aqueles que se dizem religiosos às vezes não têm.

A grande força de Colette, $\mathrm{e}$ lalvez o que tenha desapontado a crítica de sua época, reside na falla absoluta de pretensão a fazer obra filosólica. Em momento algum ela quis se transformar num dos muitos "mâttres à penser" de que a França lanto se orgulha. A subversão praticalda por Colette em sua própria vida pessoal e na obra que deixou passa por caminhos que nada têm a ver com a filosolia, a polílica ou qualquer ideologia. Seu grande valor consiste antes de mais nada em ter mantido uma autenticidade a toda prova, só recriando falos e pessoas a partir de experiências realmente vividas. Uma altitude bastante inćdila para a época foi a coragem de expor seu íntimo sem maquilagem nenhuma, contrariando uma vaidade feminina que não permilia nem a seu companheiro vê-la sem eslar devidamente poutiće.

Com a força de sua arle, e pela posição de destaque que ocupava na sociedade, além do carisma natural que seduzia as pessoas à sua volla, poderia facilmente ter liderado um dos movimentos feminislas tão em moda na época. Não só nĩo o fez mas, numa atitude aparentemente contraditória, sempre olhou com uma ponta de ironia as mulheres que queriam a lodo custo se igualar aos homens, ou reivindicar absoluta paridade de condições. Apesar de ler sempre desaliado a opinião pública, pois nunca deixou de seguir seus impulsos, sempre revelou suficientc bom senso para accilar as diferenças enlre a cssência masculina c a feminina.

No entanto, as figuras masculinas que povoam seu vasto universo, comparadas às forles figuras femininas que, já sabemos, são criadas à imagem e semeIhança da autora, em nada podem ser consideradas superiores. Ao contrário, seus principais heróis (dos quais o protótipo ć o célebre Chéri) são figuras sem consistência psicológica, de uma fragilidade normalmente atribuída ìs mulheres, e sempre precisando de uma mulher forte ao seu lado para sobreviver.

Numa tese dedicada a este assunto, com o sugestivo título de $L$ \%omme objet chez Colette, Marcelle Biolley-Godino demonstra com farla documentação que, ná obra de Colette, Demeter vence a luta sobre Vênus ou, Iraduzido em pálávras mais pobres, o/apego à lerra (leia-se: "a Sido") lem uma força muito maior do que a presença do amor na vida da autora.

Anne A. Kelchum, em Colette ou La naissance du jour, empreende uma espécie de Irabalho de reabilitação da obra de Colette, mostrando o quanto foi injustiçada pela crílica, que a censurava por excesso de popularidade, o que quase sempre é considerado um grave defeito pela intelligentsia de todas as latitudes. Colejando etapas de vida e análise da obra, extrai as linhas mestras do pensamento da autora. No capítulo que trata das relações homem/mulher, faz uma observação muito pertinente que retoma as teses de Biolley-Godino: 

1991.

Le texte de Colelle tend à relever que cel aspect parfois oblus du caractère masculin n'esı pas do à quelque infériorité de l'homme en face d'une inluition féminine inćgalable et innéc - mais plutôt le résultal du peu de mal qu'il se donne pour comprendre sa compagne: landis qu celle concentre son intérêt sur lui, s'atlache avec une minulie de maniayue à une infinilé de délails qu'il jugerait méprisables, l'homme s arrêle peu à ces jeux de palience el choisil de porler toule son allention à ses "aflaires", aux destinées problématicues de l'univers ou de son portefeuille, qu'il considère plus dignes d'intérêt $\mathbf{1 2}^{2}$.

O que Colelle parece censurar em seu cher ennemi é a falla de lempo ou de paciencia que the impede de valorizar as liligranas dos sentimentos que para a mulher estão cm primeiro lugar.

O valor da obra de Colelle eslá exalamente nacuilo que os crílicos de sua Época não sabiam ou não podiam ver. Todo o espaço concedido ao longo de sua obra às sensações, ao minucioso comentário de ludo o que se refere ao cotidiano, sem hierarquias nem discriminações, privilegiando acima de tudo a nalureza, só podia ser visto como vulgar numa época que, pela superticialidande e o gosto do arlifício, bem poderia ser comparada alo hipócrila século XVII francês.

Coletle, assim como Proust, leve o ingrato papel de ser um escritor de transiçĩo, como aponta de mancira muito feliz Anne A. Ketchum:

Nous touchons là à l'essentiel de l'apporl de Coletle au roman moderne; apport qui l'apparente à Prousı, son contemporain. La réalité contingente, visible à lous et qu'elle al su peindre comme personne, n'esl qu une part de l'univers autrement complexe dont elle eut la passion. Car alors même qu'elle peint le monde où nous vivons, celle lerrienne sonde aussi l'invisible, la réalité enfouic au plus profond de l'être cl du sentiment"13

C'est parce qu'un petit nombre d'écrivains, avec Colctle, ont pleinement ressenti l'arbilraire des conventions du genre romanesque qu'ils s'efforçaicnt pourtant de respecter que leurs sucesseurs ont pu faire lable rase de ces conventions de façon aussi radicale. C'est done dans leur oeuvre - el non dans celle des chels de file d'aujourd hui - que les historiens du roman iront "ćprouver" la crise à láuuelle les ocuvres d'aujourd" hui proposent des solutions possibles, mais qu'elles ne permellent pas toujours de sentir. Sans leur intermédiaire, la suppression du sujet comme tel, de l'intrigue el des personnages serait inintelligible ${ }^{14}$

(12) Kekchum, Anne A., Coletle ou La maissance der jour. Paris: Lettres Mexlernes, 1968, p. 211.

(13) Id., p. 283.

(14) Id., pp. 284/285. 
Acontece que, já no umbral do século XXI, após ter experimentado a dissolução do sujeito e outras contribuições da pós-modernidade, continuamos a nos sentir atraídos pela obra de Coletle, que tem o delicioso sabor dos pratos de antigamente, não pela sofisticação do preparo, mas pela genuinidade dos ingredientes.

O exemplo que ela nos dá é a simples e elementar capacidade de prestar ouvidos a todas as vozes do mundo vegetal, animal c mineral, guias seguros para o autoconhecimento.

Nós que aprendemos a nos comunicar cada vez melhor com máquinas mirabolantes, não só deixamos de nos interessar pelo próximo, más não conseguimos resolver o menor problema pessoal sem recorrermos a um número cada vez mais diversificado de especialistas, gurus e terapcutas.

Como fazer para voltarmos a ser "dignos" de compreender a linguagem da nalureza e, portanto, a nossa própria e a do oulro? Talvez, no momento cm que a volla a essa naturalidade se torna crucial para a sobrevivência do planeta, a voz de alguém como Colette possa continuar a produzir seus frutos.

A trajetória de sua vida e obra talvez possa contribuir para nos convencer de que nunca houve nem haverá outro caminho para o autoconhecimento a não ser o do aprendizado com os recursos de que a natureza dotou a todos nós.

Olhando em perspectiva todo o caminho percorrido por Coletle, a distância psicológica que separa a jovem rebelde e irreverente, acostumada a dominar e a seduzir as pessoas à sua volaa, da octogenária que já foi comparada por algum crítico a Montaigne, pela sabedoria e estoicismo, vemos nitidamente traçado o caminho de um percurso iniciático. A forma cireular de suá predileção, repetida várias vezes nas bolas de vidro que colecionava e que a fascinavam, é a metáfora desse tempo cíclico.

A última palavra pronunciada por Colette $\mathrm{cm}$ seu leito de morte: "Regarde!" (eco dos apelos inúmeras vezes lançados por sua mãe, e sempre atendidos com maravilhamento pela filha), nos dá a certeza de que a semente planlada por Sido não caíra em terreno estéril.

\section{BIBLIOGRAFIA}

BEAUmont, Germaine et PARINAUd, André. Colettc par elle-même. Paris: Seuil, "Écrivains de toujours", 1951.

BIOLLEY-GODINO, Marcelle. L 'homme objet chez Colett'. Paris: Klincksieck, 1972.

CliAUVIìrRE, Claude. Colette. Paris: Firmin Didot et Cie, 1931.

COLETTE - Chéri. Paris, Fayard, 1920.

La fin de Chéri. Paris, Flammarion, 1953.

La maison de Claudine. Paris: Hachette, 1960.

La naissance du jour. Paris: Garnier-Flammarion, 1969. 
I.I VOLSI, Angela. Coletle revisitach. Língua e Llleralura, v. 16, n. 19, p. 125-145, 1991.

Le fanal bleu. Paris: Ferenczi, 1949.

Paris de ma fenêtre. Genève: Ed. du Milieu du Monde, 1944.

L'étoile Vesper. Genère: Ed. du Milieu du Monde, 1946.

GOUDEKEI, Maurice. Prés dk' Cole'tle. Paris: Plammarion, 1956.

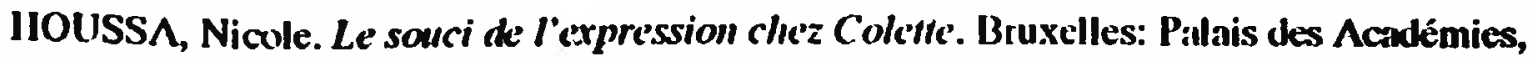
1958.

KETCIIUM, Anne A.. Coleffe on La naissance du jour. Paris: Lettres Modernes, 1968.

LE IIARDOUN, Maria. Coletle. Paris: Editions Universitaires, 1956.

PROUST, Marcel. Le kemps retroutr. Paris: Gallimard, 1954.

RAAPIIORST-ROUSSEAU, Madeleine. Col'fle - Sa vie et son art. Paris Nizet, 1964.

RESCII, Yannick. Corns féminin, corps rexulel. Paris: Klincksieck, 1973.

REYMOND, Evelyne. Le rire de Colefte. Paris: Nizet, 1988.

RQ́SUMÉ: Un regard lancé sur le singulier ilinéraire de la vie el de l'ueuvre de Cotelle (Gabrielle-Sidonnie Colelle - Saint-Sauveur-en-Puisaye, 1837; Paris, 1954), uni rachèle un insounpçonné cốté ssöque, invisible à première vue. L'veuvre de Culette est vue cumme un chemin initiatique, dunt ke but est de récuptrer une sagesse ancestrale, legs que l'nulteur a reçu de sa mère, Sich, qui l'avail imitite a la communion avec la nature. 